\title{
Numerical Study on the Required Surrounding Gas Conditions for Stable Autoignition of an Ethanol Spray
}

\author{
Hironori Saitoh (D, Koji Uchida, and Norihiko Watanabe \\ Department of Mechanical Engineering, Sojo University, Ikeda 4-22-1, West Ward, Kumamoto 860-082, Japan \\ Correspondence should be addressed to Hironori Saitoh; saitoh@mec.sojo-u.ac.jp
}

Received 18 January 2019; Revised 20 May 2019; Accepted 15 July 2019; Published 17 October 2019

Academic Editor: Kalyan Annamalai

Copyright (c) 2019 Hironori Saitoh et al. This is an open access article distributed under the Creative Commons Attribution License, which permits unrestricted use, distribution, and reproduction in any medium, provided the original work is properly cited.

\begin{abstract}
This study deals with the development of controlled-ignition technology for high-performance compression ignition alcohol engines. Among the alcohol fuels, we focus on ethanol as it is a promising candidate of alternative fuels replacing petroleum. The objective of this study is to reveal the physical and chemical phenomena in the mixture formation process up to autoignition of an ethanol spray. In our previous numerical study, we showed the mixture formation process for gas oil and ethanol sprays in the form of spatial excess air ratio and temperature distributions inside a spray and their temporal histories from fuel injection. The results showed a good agreement with those of theoretical analysis based on the momentum theory of spray penetration. Calculation was also confirmed as reasonable by comparing to the experimental results. Through the series of our experimental and numerical studies, the reason for poor autoignition quality of an ethanol spray was revealed, that is, difficulty in simultaneous attainments of autoignition-suitable concentration and temperature in the spray mixture formation due to its fuel and thermal properties of smaller stoichiometric air-fuel ratio and much greater heat of evaporation compared to conventional diesel fuels. However, autoignition of an ethanol spray has not been obtained yet in either experiments or numerical analysis. As the next step, we numerically examined several surrounding gas pressure and temperature conditions to make clear the surrounding gas conditions enough to obtain stable autoignition. One of the commercial CFD codes CONVERGE was used in the computational calculation with the considerations of turbulence, atomization, evaporation, and detailed chemical reaction. Required surrounding gas pressure and temperature for stable autoignition with acceptable ignition delay of an ethanol spray and feasibility of the development of high-performance compression ignition alcohol engines are discussed in this paper.
\end{abstract}

\section{Introduction}

Needless to say, utilization of natural and renewable energy has been highlighted under the situation of global energy and environmental problems such as oil reserve depletion and climate change. Present social and industrial activities depend on the hydrocarbon combustion. In addition to the automotive industry, a large amount of petroleum is consumed in various kinds of industries. Heavy duty oil is the main fuel of burners used for temperature control in green houses where many kinds of vegetables, fruits, and flowers are growing and is also used for drying of agricultural and fishing products such as tea leaves and seaweed. A heat pump has better efficiency to obtain such low-level heat. A cogeneration system with a diesel engine and a heat pump is one of the effective ways for saving energy resources. This study deals with the development of high-performance diesel engines fueled by biomass-based alcohol. In addition to the power unit of vehicles, diesel-type high-performance engines flexible for any kinds of biofuels including bioethanol can be applied to agriculture and fishing industries as a small-sized personal use electrical power generation system. That is, they can be one of the essential components for the cogeneration system previously introduced and can also be applied as a large-sized backup system for huge electrical power generation plants. Stable electric power supply can also be realized by the best combination with any other natural energy utilization such as solar power, wind, and biomass if the above proposed high-performance alcohol diesel engine is developed. When renewable biofuel is 
their all power resource, a sustainable community can be established, as shown in Figure 1. Although electrical energy and thermal energy are required for biofuel production, such energy can also be supplied by alcohol diesels, solar power, and wind power. Therefore, success of this study induces the promotion of renewable biomass energy and a big contribution against the worldwide energy and environmental problems. The scale of the sustainable community depends on energy supply-demand relations. Therefore, the amount of feedstocks and productivity of biofuel have to be considered when the scale of the sustainable community is decided. Local areas in countryside have larger potential of biomass production (large-scale biomass plantation) compared to urban cities. This generates various kinds of new businesses that correspond to the increase of employees; as a result of such social movements, civil life and industrial activities in each local community can be changed. Especially in Asian countries such as Thailand and Indonesia, R\&D of biomass energy utilization has been promoted as their national energy strategies. If the above introduced sustainable community appears around the world, lifestyle and industrial activities must be changed. Although energy-saving and economic growth is the trade-off relation between each other, this compatibility seems to be possible with the development of biomass energy production and conversion technologies. This is the authors' expected future image and the motivation of this research topic.

The goal of our research is the establishment of controlled-ignition technology for high-performance compression ignition alcohol engines. Among alcohol fuels, we focused on ethanol as it is a promising candidate of alternative fuels replacing petroleum. The biggest challenge in the development of alcohol diesels is ignition control because of well-known poor autoignition quality. A lot of feasibility studies of alcohol diesel were conducted extensively in the 1990s. In the history of alcohol diesel research and development, the approaching way of ignition improvement is categorized by two points of view: one is on the engine-side measures by employing ignition-assist devices such as a glow plug [1-4], spark plug [5-7], or heating surface [8] and the other is on the fuel-side measures by adding small amounts of the ignition improver $[9,10]$. Almost all of these studies just concerned to seek the optimum configurations of ignition-assist devices and amount of additives within each examined engine and their performance. The authors have investigated the conditions for stable autoignition of an alcohol spray as fundamental studies and intensively reported this research.

\section{Previous Studies and Objective}

2.1. Reason for Poor Autoignition Quality of Alcohol Fuels. As the general understanding of the conditions of autoignition, there are two essential factors in the mixture formation process. One is the concentration factor: a mixture has to be in a mixing ratio sufficient to advance chemical reactions. The other is a temperature factor: temperature of the mixture has to exceed a certain value so

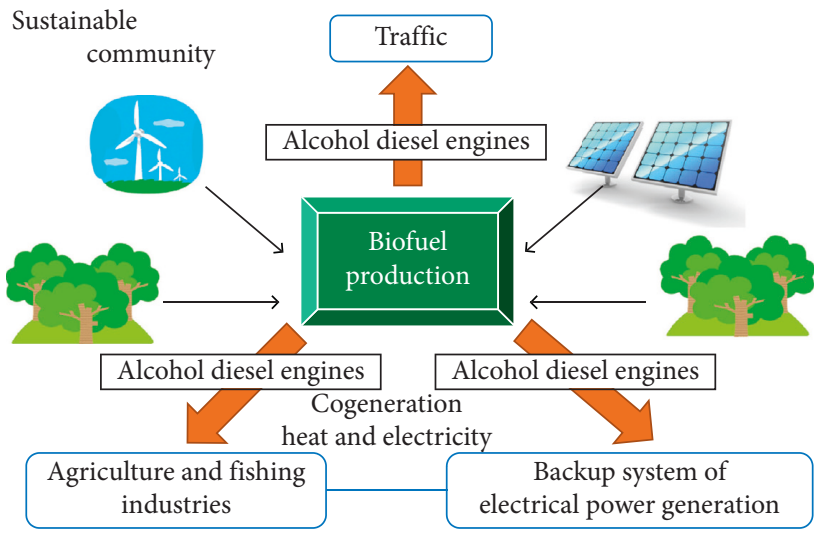

Figure 1: Conceptual figure of the sustainable community with biomass energy utilization.

that precombustion chemical reactions are promoted. Based on this recognition, the concentration and temperature factors for autoignition are defined as follows:

$$
\begin{aligned}
& \text { concentration factor: } \lambda_{t i p}=1, \\
& \text { temperature factor: } T_{\mathrm{spm}}>T_{\mathrm{ig}} .
\end{aligned}
$$

In equation (1), $\lambda_{\text {tip }}$ indicates the mean excess air ratio of a spray tip. Excess air ratio $(\lambda)$ is defined as actual air-fuel ratio/stoichiometric air-fuel ratio; therefore, in case of $\lambda=1$, mixture concentration is the stoichiometric air-fuel ratio, $\lambda>1$ corresponds to the lean mixture, and $\lambda<1$ implies rich mixture. $T_{\text {spm }}$ and $T_{\text {ig }}$ in equation (2) represent, respectively, the mean temperature of a spray and minimum ignition point of fuels. Figure 2 shows the result of theoretical analysis on the spray mixture formation process for gas oil and ethanol [11]. This indicates the histories of mixture concentration and temperature from fuel injection, and they were evaluated, respectively, as the excess air ratio of a spray tip $\left(\lambda_{\text {tip }}\right)$ and mean temperature of a spray $\left(T_{\text {spm }}\right)$. The value of $\lambda_{\text {tip }}$ was calculated based on the spray momentum theory proposed by Wakuri [12]. In this theory, the spray is assumed to be the air-vapour two-phase flow with instantaneous evaporation of injected fuel. According to this theory, reaching distance of a spray and its excess air ratio are expressed as the function of time from fuel injection. Stable autoignition seems to occur if the above introduced temperature factor $\left(T_{\mathrm{spm}}>T_{\mathrm{ig}}\right)$ is satisfied by time when the concentration factor $\left(\lambda_{\text {tip }}=1\right)$ is cleared. Required heat that increases temperature of the spray up to $T_{\text {ig }}$ is expressed as follows:

$$
Q=G_{\mathrm{f}}\left[c_{\mathrm{fl}}\left(T_{\mathrm{b}}-T_{\mathrm{o}}\right)+\gamma_{\mathrm{f}}+c_{\mathrm{fg}}\left(T_{\mathrm{ig}}-T_{\mathrm{b}}\right)\right] .
$$

First and third terms in equation (3) correspond to the apparent heat in liquid and gas phases, respectively, and the second term means the latent heat of evaporation. Variable $\left(G_{\mathrm{f}}\right)$ is the mass of injected fuel that also is the function of time. Mean temperature $\left(T_{\mathrm{spm}}\right)$ was obtained from the following equation as instantaneous heat balance was assumed to be satisfied: 


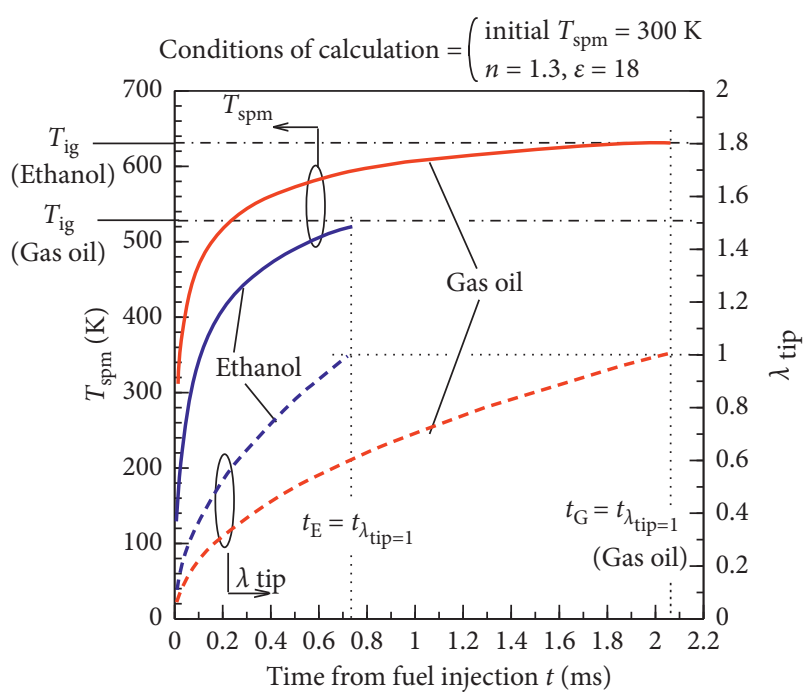

Figure 2: Estimations of $\lambda_{\text {tip }}$ and $T_{\text {spm }}$ histories for ethanol and gas oil from fuel injection.

$$
G_{\mathrm{f}}\left[c_{\mathrm{fl}}\left(T_{\mathrm{b}}-T_{\mathrm{o}}\right)+\gamma_{\mathrm{f}}+c_{\mathrm{fg}}\left(T_{\mathrm{spm}}-T_{\mathrm{b}}\right)\right]=G_{\mathrm{a}} c_{\mathrm{ac}}\left(T_{\mathrm{c}}-T_{\mathrm{spm}}\right) .
$$

It can be understood from Figure 2 that autoignition of a gas oil spray is dominated by the concentration factor because $T_{\text {spm }}$ is higher than $T_{\text {ig }}$ when mixture concentration reached $\lambda_{\text {tip }}=1$. On the contrary, for an ethanol spray, $T_{\text {spm }}$ did not reach $T_{\text {ig }}$ when $\lambda_{\text {tip }}=1$, and leaner situation is easily expected by time when $T_{\text {spm }}>T_{\text {ig. }}$. This result of theoretical analysis allows us to draw one hypothesis on the reason for poor autoignition quality of an alcohol spray, that is, difficulty in simultaneous attainments of concentration and temperature factors during the mixture formation process due to smaller stoichiometric air-fuel ratio $\left(L_{t h}\right)$ and much larger latent heat of evaporation $(\gamma)$ of ethanol compared to gas oil (see Table 1). If this hypothesis is correct, the autoignition quality of an alcohol spray must be improved with retardation of lean situation and faster temperature rise. Based on this recognition, we proposed hot EGR (exhaust gas recirculation) as an idea of autoignition quality improvement for alcohol sprays and experimentally confirmed the effectiveness of hot EGR to obtain shorter ignition delay by using a small DI diesel engine.

Through the above introduced studies, the governing parameters of autoignition are categorized by two aspects. One is fuel properties, especially stoichiometric air-fuel ratio and latent heat of evaporation. The other is surrounding gas conditions such as pressure, temperature, and oxygen concentration. During this five years, the effects of each autoignition governing parameter on ignition delay of ethanol-diethyl ether blend fuels (by changing blend ratio) have been experimentally investigated by high-speed visualization of the mixture formation process up to autoignition in a constant-volume combustion chamber, and the $3 \mathrm{D}$ map/database that indicates how great is the influence on ignition delay for each tested fuel was established and reported $[13,14]$.
TABLE 1: Fuel properties.

\begin{tabular}{lcc}
\hline \multirow{2}{*}{ Properties } & \multicolumn{2}{c}{ Fuel notation } \\
& Ethanol & Gas oil \\
\hline Stoichiometric $A / F$ ratio $L_{t h}(\mathrm{~kg} / \mathrm{kg})$ & 9.01 & 14.6 \\
Density $\rho_{\mathrm{f}}\left(\mathrm{kg} / \mathrm{m}^{3}\right)$ & 785 & 825 \\
Specific heat $(\mathrm{liquid}) c_{\mathrm{fl}}(\mathrm{kJ} /(\mathrm{kg} \cdot \mathrm{K}))$ & 2.723 & 2.372 \\
Specific heat $(\mathrm{gas}) c_{\mathrm{fg}}(\mathrm{kJ} /(\mathrm{kg} \cdot \mathrm{K}))$ & 2.329 & 1.915 \\
Boiling point $T_{\mathrm{b}}(\mathrm{K})$ & 351.7 & $443 \sim 663$ \\
Heat of evaporation $\gamma_{\mathrm{f}}(\mathrm{kJ} / \mathrm{kg})$ & 854.8 & 187.2 \\
Minimum ignition point $T_{\mathrm{ig}}(\mathrm{K})^{*}$ & 636 & 530 \\
Lower heating value $\mathrm{Hu}(\mathrm{MJ} / \mathrm{kg})$ & 26.8 & 44.4 \\
\hline
\end{tabular}

*Under the atmospheric pressure condition.

2.2. Objective. Although the reason for poor autoignition quality of an ethanol spray was revealed based on our previous theoretical and experimental studies, we just observed the spray mixture formation process by the shadowgraph method and showed the relationship between ignition delay and surrounding gas conditions, and the internal structure of a spray is still at question. In order to develop the controlled-autoignition technology, the spray mixture formation process up to autoignition as physical and chemical phenomena has to be revealed. The objective of this study, therefore, is to make numerically clear the conditions of stable autoignition of an ethanol spray from the viewpoint of instantaneous spatial mixture concentration and temperature distributions inside a spray and their temporal histories from fuel injection.

\section{Numerical Analysis}

3.1. Computational Domain and Mesh Geometry. A constant-volume electrical heating chamber, as shown in Figure 3(a), was employed for high-speed visualization of spray mixture formation up to autoignition in our previous research. The size of the computational domain, as shown in Figure 3(b), is smaller than the volume of the combustion chamber to save simulation time. However, the size of the computational domain was decided to be large enough to simulate the physical and chemical phenomena without the collision of a spray to the chamber wall. Table 2 presents the comparison of specifications between the combustion chamber and the computational domain. In order to compare the results between experiment and numerical analysis, conditions of fuel injection were the same as those in the experiment. Table 3 shows the mesh geometry employed in the numerical analysis. The base grid size was $4 \mathrm{~mm}$. A fine mesh of $0.5 \mathrm{~mm}$ was set in the expected area where mixture formation occurs. The entity of the fine mesh is cone shaped, as shown in Figure 3(b) (light blue region), and its geometry is presented as the entry "FE (fixed embedding) fine mesh" in Table 3. The commercial CFD code CONVERGE used in the numerical analysis has an automatic mesh refinement function named "AMR" (adaptive mesh refinement). We applied AMR for velocity, temperature, and chemical species, as listed in Table 3. For each grid point, AMR activation is judged by the "subgrid criterion" comparing the calculated results of velocity, 


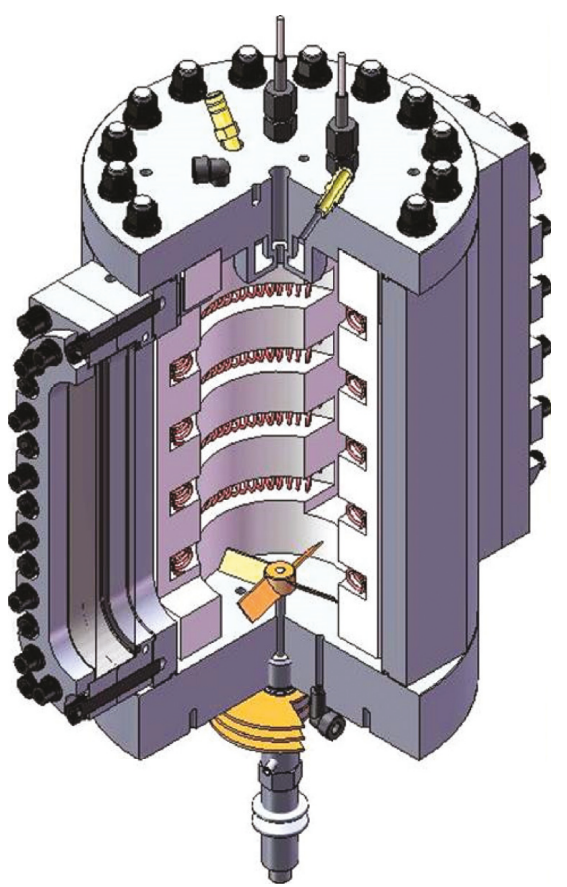

(a)

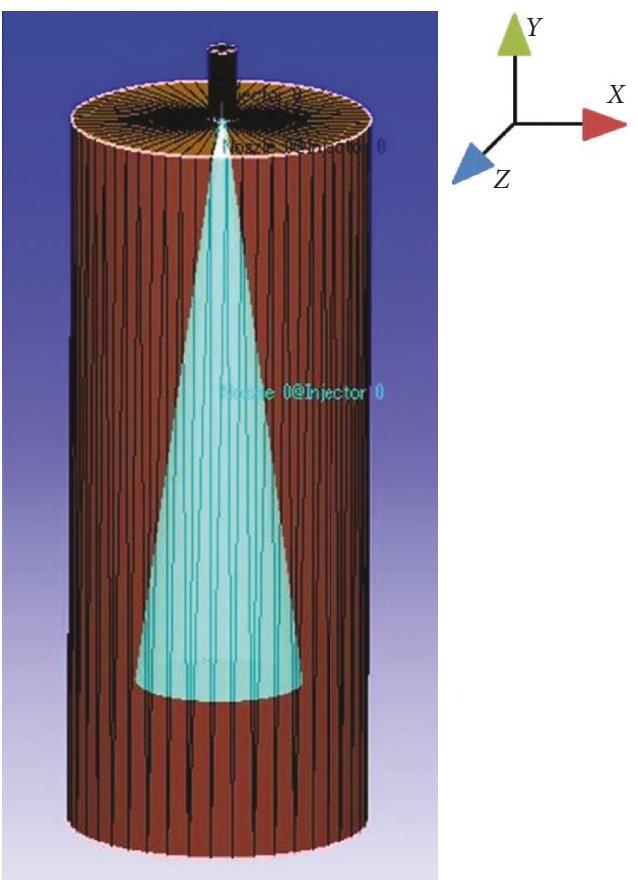

(b)

FIgURE 3: Comparison between the constant-volume electrical heating chamber (a) and the computational domain (b).

TABLE 2: Comparison of specification between the combustion chamber and the computational domain.

\begin{tabular}{lcc}
\hline Specification & Constant-volume chamber & Simple constant-volume chamber model \\
\hline Chamber size $(\varphi \times H)$ & $150 \mathrm{~mm} \times 420 \mathrm{~mm}$ & $82.6 \mathrm{~mm} \times 200 \mathrm{~mm}$ \\
Volume & $7250 \mathrm{cc}$ & $1072 \mathrm{cc}$ \\
\hline Injection pressure & & $50 \mathrm{MPa}$ \\
Injection duration & $4.6 \mathrm{~ms}$ \\
Injector nozzle type $(\Phi$ (diameter $) \times N$ (number) $)$ & Hole type $(0.14 \mathrm{~mm} \times 1)$ \\
\hline
\end{tabular}

TABLE 3: Specification of the mesh in the computational domain.

\begin{tabular}{|c|c|c|c|}
\hline \multirow{3}{*}{ Base grid } & \multicolumn{2}{|c|}{$X$} & $4 \mathrm{~mm}$ \\
\hline & \multicolumn{2}{|c|}{$Y$} & $4 \mathrm{~mm}$ \\
\hline & \multicolumn{2}{|c|}{$Z$} & $4 \mathrm{~mm}$ \\
\hline \multirow{5}{*}{ FE (fixed embedding) fine mesh } & \multicolumn{2}{|c|}{ Entity type } & Cone: “INJECTOR" \\
\hline & \multicolumn{2}{|c|}{ Scale : base grid $\times 2^{\wedge}(-$ scale $)$} & $3: 4 \mathrm{~mm} \times 2^{-3}=0.5 \mathrm{~mm}$ \\
\hline & \multicolumn{2}{|c|}{ Radius1 } & $1 \mathrm{~mm}$ \\
\hline & \multicolumn{2}{|c|}{ Radius2 } & $23 \mathrm{~mm}$ \\
\hline & \multicolumn{2}{|c|}{ Length } & $160 \mathrm{~mm}$ \\
\hline \multirow{4}{*}{ AMR (adaptive mesh refinement) } & Velocity & $\begin{array}{l}\text { Max. embedding scale } \\
\text { Subgrid criterion }\end{array}$ & $\begin{array}{c}6: 4 \mathrm{~mm} \times 2^{-6}=0.0625 \mathrm{~mm} \\
1.0 \mathrm{~m} / \mathrm{sec}\end{array}$ \\
\hline & \multirow{2}{*}{ Temperature } & Max. embedding scale & $6: 4 \mathrm{~mm} \times 2^{-6}=0.0625 \mathrm{~mm}$ \\
\hline & & Subgrid criterion & $2.5 \mathrm{~K}$ \\
\hline & Species & $\begin{array}{l}\text { Max. embedding scale } \\
\text { Subgrid criterion }\end{array}$ & $\begin{array}{c}5: 4 \mathrm{~mm} \times 2^{-5}=0.125 \mathrm{~mm} \\
0.0001 \text { mole fraction }\end{array}$ \\
\hline
\end{tabular}

temperature, and chemical species to their previous time step results at the same grid. A minimum mesh size of $0.0625 \mathrm{~mm}$ was applied by AMR in the numerical analysis for correct calculation. The maximum number of mesh was approximately 1.5 million under meshing conditions mentioned above. The finer mesh which has around 2 million meshes was also examined, however, no longer the spatial resolutions of the solution and numerical results were not changed. Thus, mesh conditions in Table 3 were adopted.

3.2. Governing Equations and Boundary Conditions. Flow and temperature fields were solved under the conservation 
TABle 4: Physical and chemical models and analysis conditions.

\begin{tabular}{|c|c|c|c|c|c|c|}
\hline Index of calculation & No. 1 & No. 2 & No. 3 & No. 4 & No. 5 & No. 6 \\
\hline Fuel & Gas oil & Ethanol & Ethanol & Ethanol & Ethanol & Ethanol \\
\hline Surrounding gas temperature $(\mathrm{K})$ & 800 & 800 & 1000 & 1000 & 1100 & 1200 \\
\hline Surrounding gas pressure $(\mathrm{MPa})$ & 2.5 & 2.5 & 6.5 & 9.0 & 5.5 & 9.0 \\
\hline Surrounding gas oxygen concentration & \multicolumn{6}{|c|}{21 vol.\% } \\
\hline Turbulence model & \multicolumn{6}{|c|}{ LES model (LES: Large Eddy Simulation) } \\
\hline Spray model & \multicolumn{6}{|c|}{ KH-RT model (KH: Kelvin-Helmholtz and RT: Rayleigh-Taylor) } \\
\hline Chemical reaction model & \multicolumn{6}{|c|}{ SAGE detailed elementary reaction model } \\
\hline
\end{tabular}

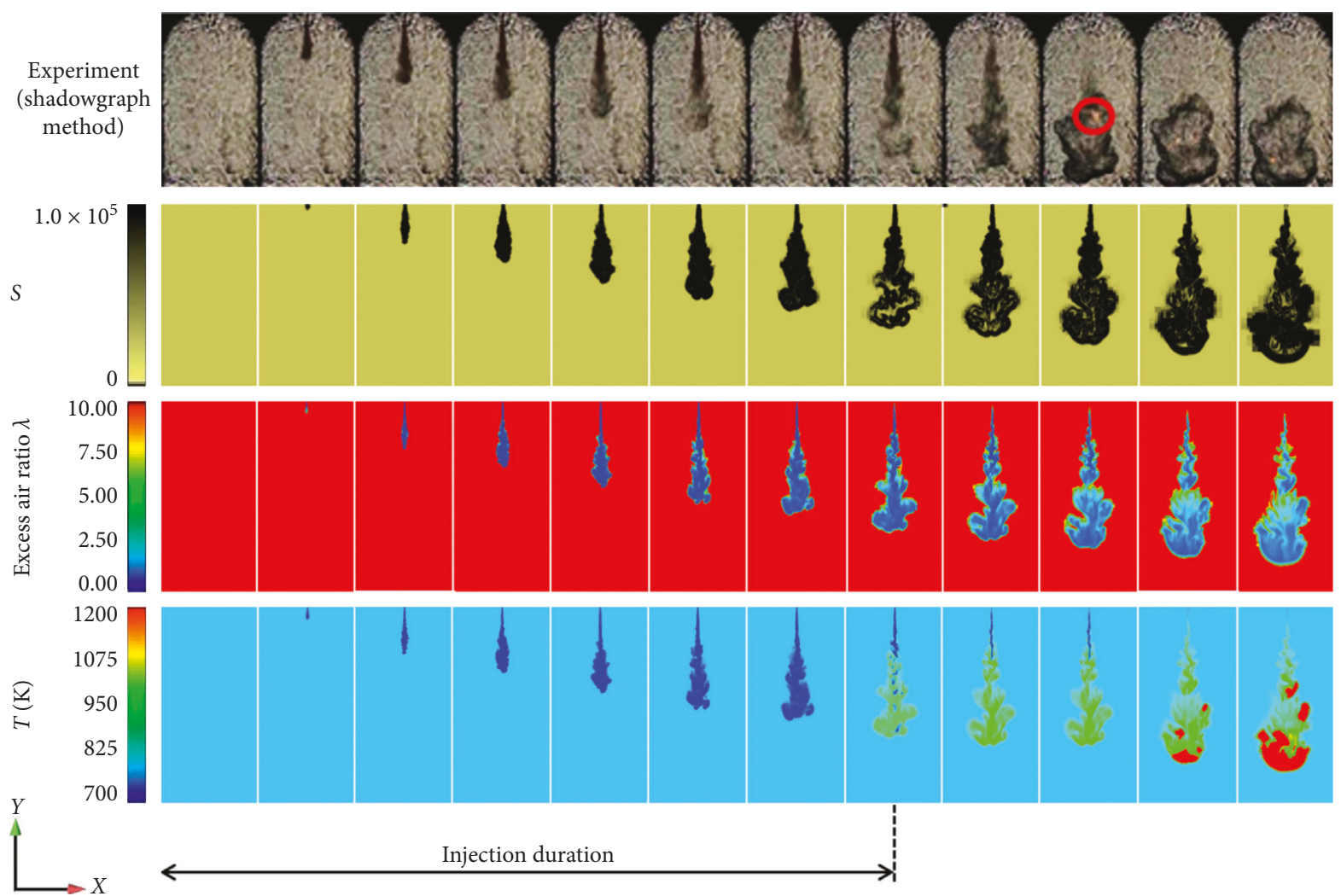

FIGURE 4: Verification of numerical analysis for a gas oil spray by comparison with the experimental result (conditions of surrounding gas: $P=2.5 \mathrm{MPa}, T=800 \mathrm{~K}$, and $\mathrm{O}_{2} 21$ vol.\%).

law of mass, momentum, and energy. A three-dimensional equation of continuity, Navier-Stokes equation, and energy equation were employed with the consideration of fluid compressibility. The transport equation of chemical species was also applied for the calculation of combustion. Flow and temperature fields were numerically solved by the finite volume method for the above introduced governing equations.

The nonslip condition was applied for the flow field at the boundary of the computational domain. The law of wall was also applied as the thermal boundary condition. The initial gas condition corresponded to the surrounding gas conditions of a fuel spray.

3.3. Physical and Chemical Models and Analysis Conditions. Large eddy simulation (LES) was used as the turbulence model. The KH-RT model, a combination of Kelvin-Helmholtz and Rayleigh-Taylor models, was employed for atomization and evaporation of fuel droplets. The detailed chemical reaction model was also used in the calculation. We referenced the chemical kinetic mechanism of ethanol proposed by Marinov [15], and it has been given open access at the website of Lawrence Livemore National Laboratory (California, USA): https:/combustion.llnl.gov/archived-mechanisms/ethanol.

Table 4 also shows the analysis conditions. Five kinds of simulations indexed No. 2-No. 6 were performed for an ethanol spray. As the first step of numerical analysis, we focused on surrounding gas pressure and temperature among the autoignition governing parameters. Then, five simulations (No. 2-No. 6) were performed under the condition of constant oxygen concentration (21 vol.\%, the same as that of normal air). Calculation of the mixture formation process up to autoignition for a gas oil spray, which is indexed No. 1 in Table 4, was also conducted and compared with the experimental result obtained in our 


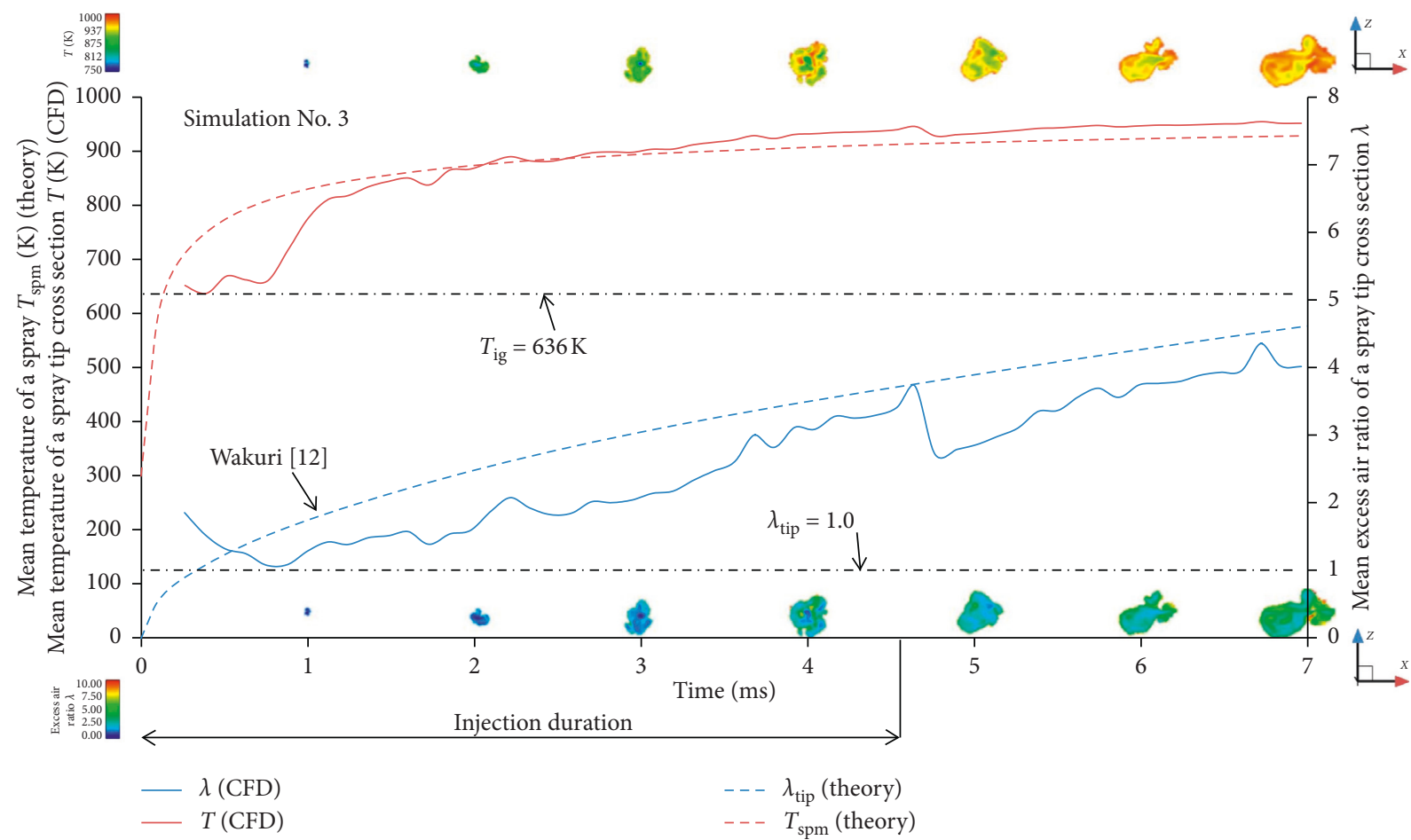

(a)

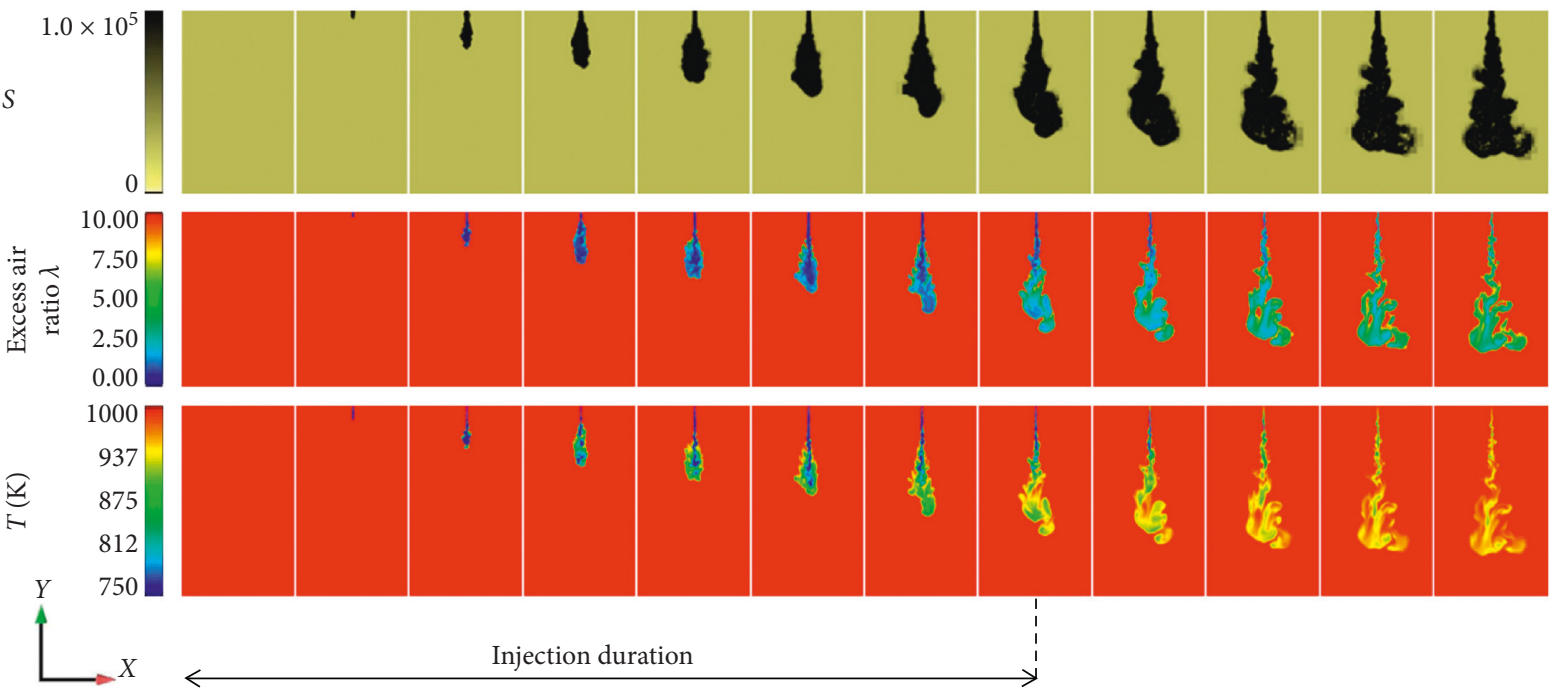

(b)

Figure 5: Results of No. 3 simulation (surrounding gas conditions: $P=6.5 \mathrm{MPa}, T=1000 \mathrm{~K}$, and $\mathrm{O}_{2} 21$ vol.\%). (a) Comparison of $\lambda$ and $T$ histories from fuel injection between numerical and theoretical calculation. (b) Visualized images of $S, \lambda$, and $T$.

previous study in order to verify the models employed in the numerical analysis.

\section{Results and Discussion}

4.1. Verification of Physical Models. Figure 4 shows the comparison of the mixture formation process up to autoignition for a gas oil spray between experiment and numerical analysis. Surrounding gas conditions were $P=2.5 \mathrm{MPa}, T=800 \mathrm{~K}$, and $21 \%$ oxygen concentration. Figure 4 consists of four sets of visualized images. The top image set shows the experimental result. In the experiments, test gas was supplied from a bomb into the chamber (as shown in Figure 3(a)) up to the initial condition of pressure. Initial gas pressure before heating was calculated based on the equation of state under the constant-volume condition. Initial gas temperature was measured by a K-type thermocouple. Inchamber gas pressure was measured with the strain gaugetype pressure sensor, and it was monitored during the experiment. Test fuel was injected into the chamber when gas pressure indicated the target value during heating. Visualization of spray mixture formation was conducted by the 


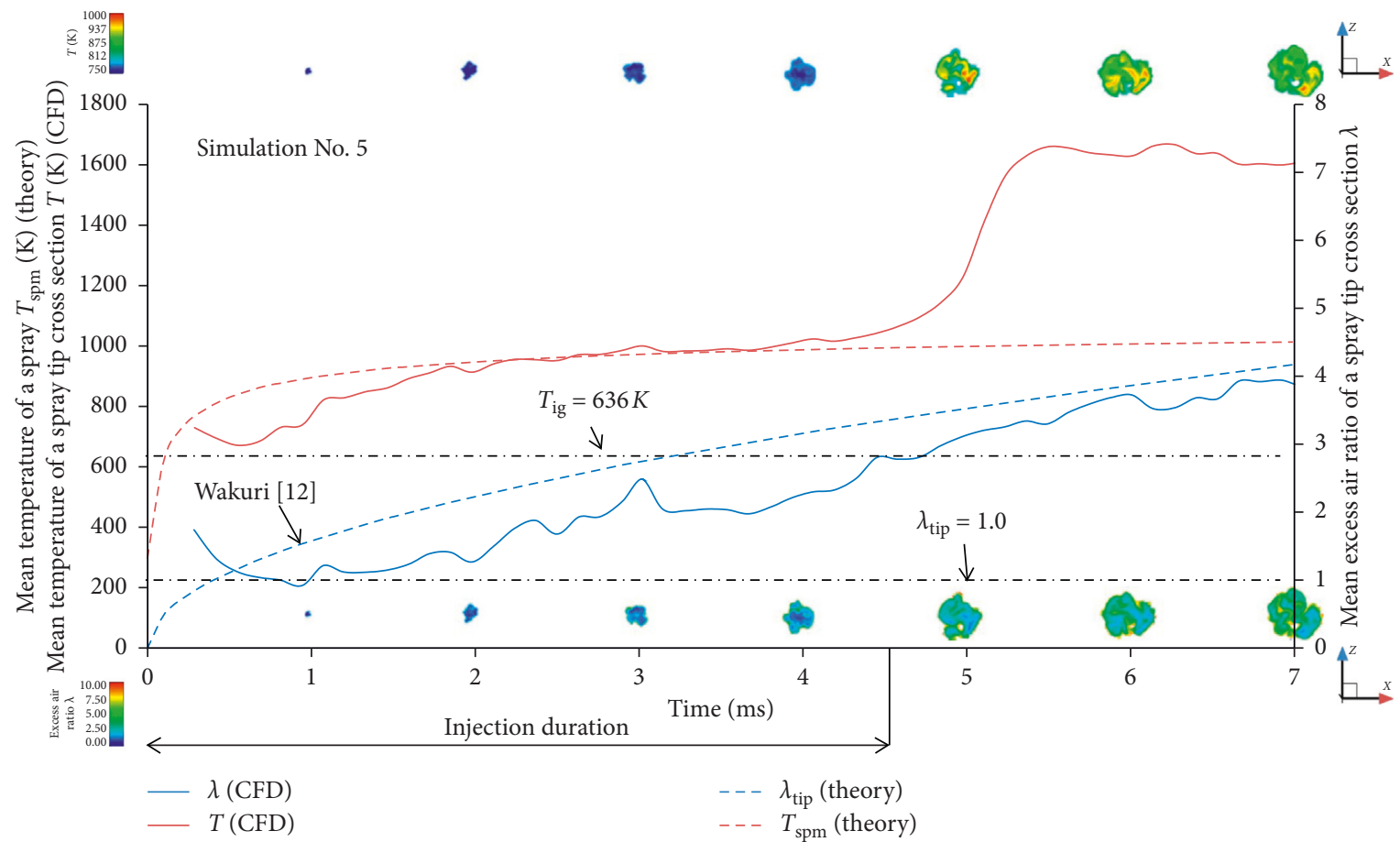

(a)

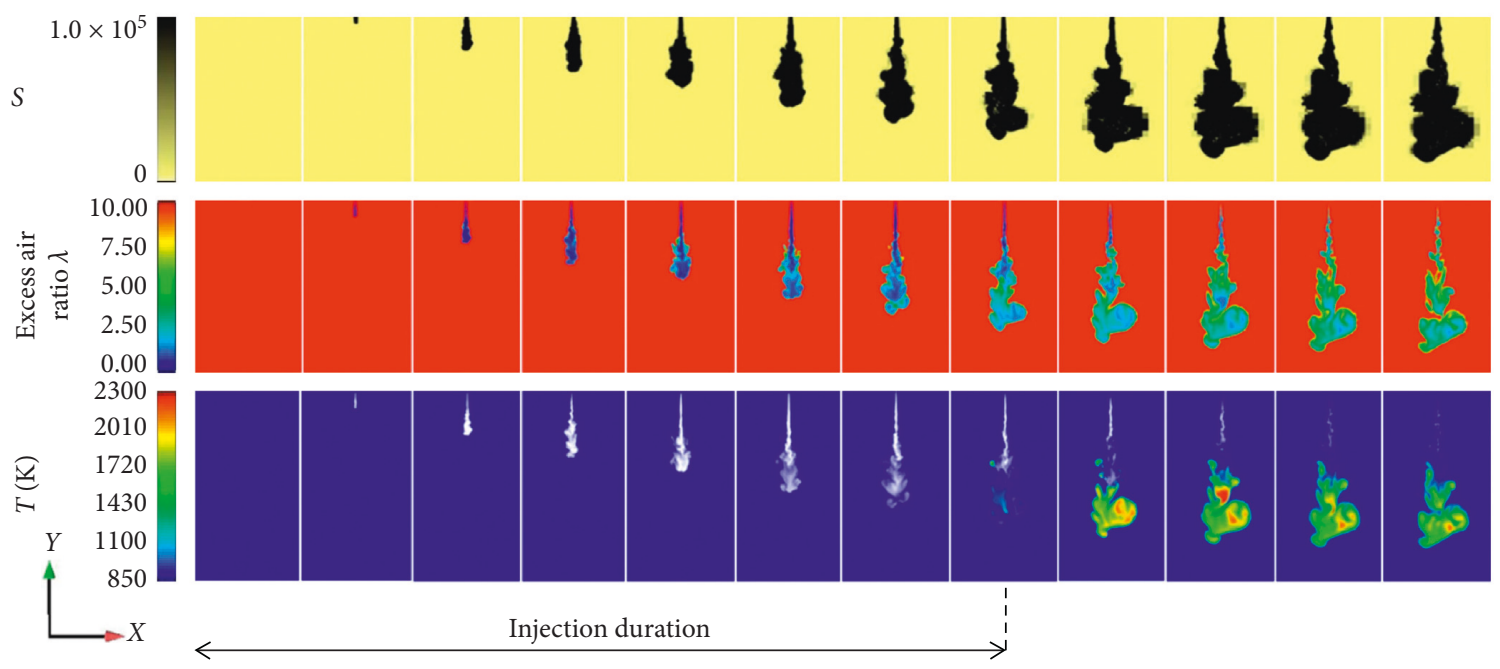

(b)

Figure 6: Results of No. 5 simulation (surrounding gas conditions: $P=5.5 \mathrm{MPa}, T=1100 \mathrm{~K}$, and $\mathrm{O}_{2} 21$ vol.\%). (a) Comparison of $\lambda$ and $T$ histories from fuel injection between numerical and theoretical calculation. (b) Visualized images of $S$ and $\lambda$.

shadowgraph method. The spray mixture formation process and autoignition phenomenon were recorded with a highspeed camera at $8000 \mathrm{fps}$. Recording was synchronized with fuel injection. The others are results of numerical analysis (from the top: shadowgraph image, excess air ratio distribution, and temperature distribution of the cross section along the spray axis). The numerical shadowgraph image was illustrated by the evaluation of the variable $S$ defined as the root sum square of second-order spatial density gradient in three directions which is expressed by

$$
S=\sqrt{\left(\frac{d^{2} \rho}{d x^{2}}\right)^{2}+\left(\frac{d^{2} \rho}{d y^{2}}\right)^{2}+\left(\frac{d^{2} \rho}{d z^{2}}\right)^{2}} .
$$

Although there is one frame difference in autoignition timing, experimental and numerical results showed good agreement. From this fact, physical and chemical models employed in the calculation seem to be reasonable. 


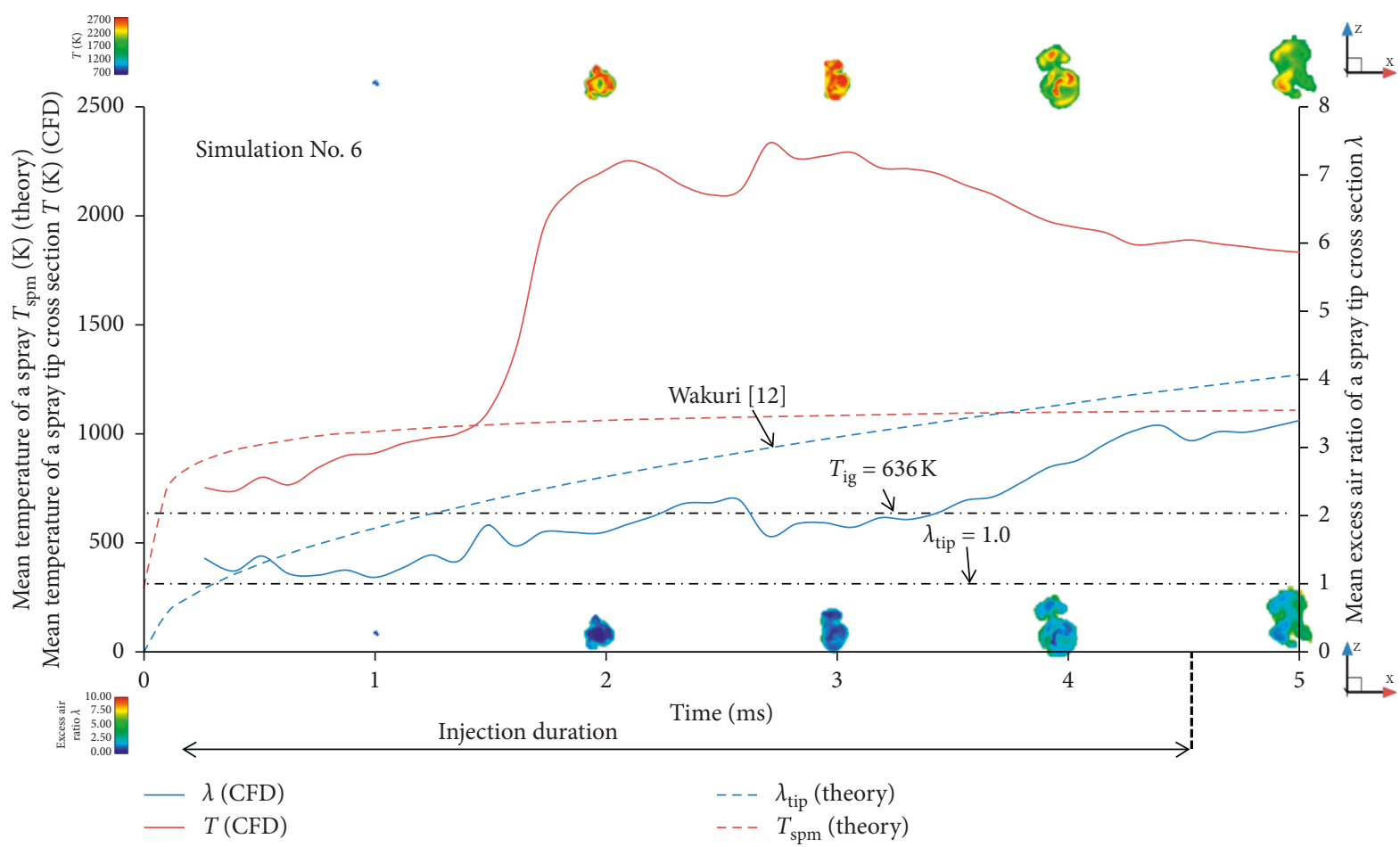

Figure 7: Results of No. 6 simulation (surrounding gas conditions: $P=9.0 \mathrm{MPa}, T=1200 \mathrm{~K}$, and $\mathrm{O}_{2} 21$ vol.\%).

4.2. Mixture Formation up to Autoignition of an Ethanol Spray. In case of No. 2 simulation $(P=2.5 \mathrm{MPa}$ and $T=800 \mathrm{~K}$; see Table 4 ), autoignition was not observed as expected. Also, no autoignition occurred in the past experiment under the same surrounding gas conditions. Surrounding gas pressure values of $5.5 \mathrm{MPa}$ (No. 5), 6.5 $\mathrm{MPa}$ (No. 3), and 9.0 MPa (Nos. 4 and 6) correspond to the compression pressure at the TDC of a CI engine in case with its compression ratio of $19.5,22$, and 28 , respectively, with the assumptions of the intake gas pressure of $0.1 \mathrm{MPa}$ and polytropic exponent of 1.35. Autoignition was observed in No. $5(P=5.5 \mathrm{MPa}$ and $T=1100 \mathrm{~K})$ and No. 6 $(P=9.0 \mathrm{MPa}$ and $T=1200 \mathrm{~K})$ simulations, while in the cases of No. $3(P=6.5 \mathrm{MPa}$ and $T=1000 \mathrm{~K})$ and No. 4 $(P=9.0 \mathrm{MPa}$ and $T=1000 \mathrm{~K})$ simulations, autoignition was not confirmed. Autoignition of an ethanol spray seemed to be dominated by surrounding gas temperature regardless of surrounding gas pressure. In order to have correct understanding of the autoignition physical and chemical mechanism, spatial mixture concentration and temperature distributions inside a spray were analyzed and compared with the momentum theory of spray penetration by Wakuri [12], as introduced in Figure 2.

Figure 5 shows the result of No. 3 simulation (conditions: $P=6.5 \mathrm{MPa}$ and $T=1000 \mathrm{~K}$ ) and that the case of autoignition did not occur. Figure 5(a) presents the comparison of $\lambda$ and $T$ histories from fuel injection between numerical and theoretical calculation. In the case of numerical analysis, $\lambda$ and $T$ were calculated as the area-averaged value of the maximum $x-z$ cross section in a spray. On the contrary, in the case of theory introduced in Section 2, the spray was assumed to be the air-vapour two-phase flow with instantaneous evaporation of injected fuel. Instantaneous heat balance was also assumed to be satisfied, and the mean temperature of a spray $\left(T_{\mathrm{spm}}\right)$ was calculated. Although $\lambda$ of CFD was smaller than that of theory, numerical and theoretical results showed the same tendency. Difference in $\lambda$ between CFD and theory seems to be attributed to the consideration of atomization and evaporation in the numerical analysis (CFD). Prior to this No. 3 simulation, autoignition was expected to occur from the theoretical prediction of $\lambda$ and $T$ because $T_{\mathrm{spm}}$ already reached the minimum ignition point of ethanol $\left(T_{\mathrm{ig}}=636 \mathrm{~K}\right)$ when the concentration factor for autoignition represented as $\lambda=1$ was achieved by fuel injection, which corresponds to simultaneous attainment of autoignition-suitable concentration and temperature during the mixture formation process. However, autoignition was not confirmed in Figure 5(b) consisting of visualized images of the numerical shadowgraph $(S)$ and $\lambda$ and $T$ distributions. No volume expansion and heat generation induced by chemical reactions recognized as ignition and combustion were observed. A similar result was obtained in No. 4 simulation (conditions: $P=$ 9.0 $\mathrm{MPa}$ and $T=1000 \mathrm{~K})$.

Figures 6(a) and 6(b) present the result of No. 5 simulation (conditions: $P=5.5 \mathrm{MPa}$ and $T=1100 \mathrm{~K}$ ). A drastic temperature rise around the timing at the end of fuel injection duration is clearly seen in Figure 6(a). At the same timing, volume expansion and temperature higher than that of surrounding gas up to $2200 \mathrm{~K}$ were observed, as shown in Figure 6(b). This result seems to be the evidence of autoignition and combustion. The mean temperature of a spray cross section reached around $1000 \mathrm{~K}$ when autoignition occurred. This value is much higher than the minimum 

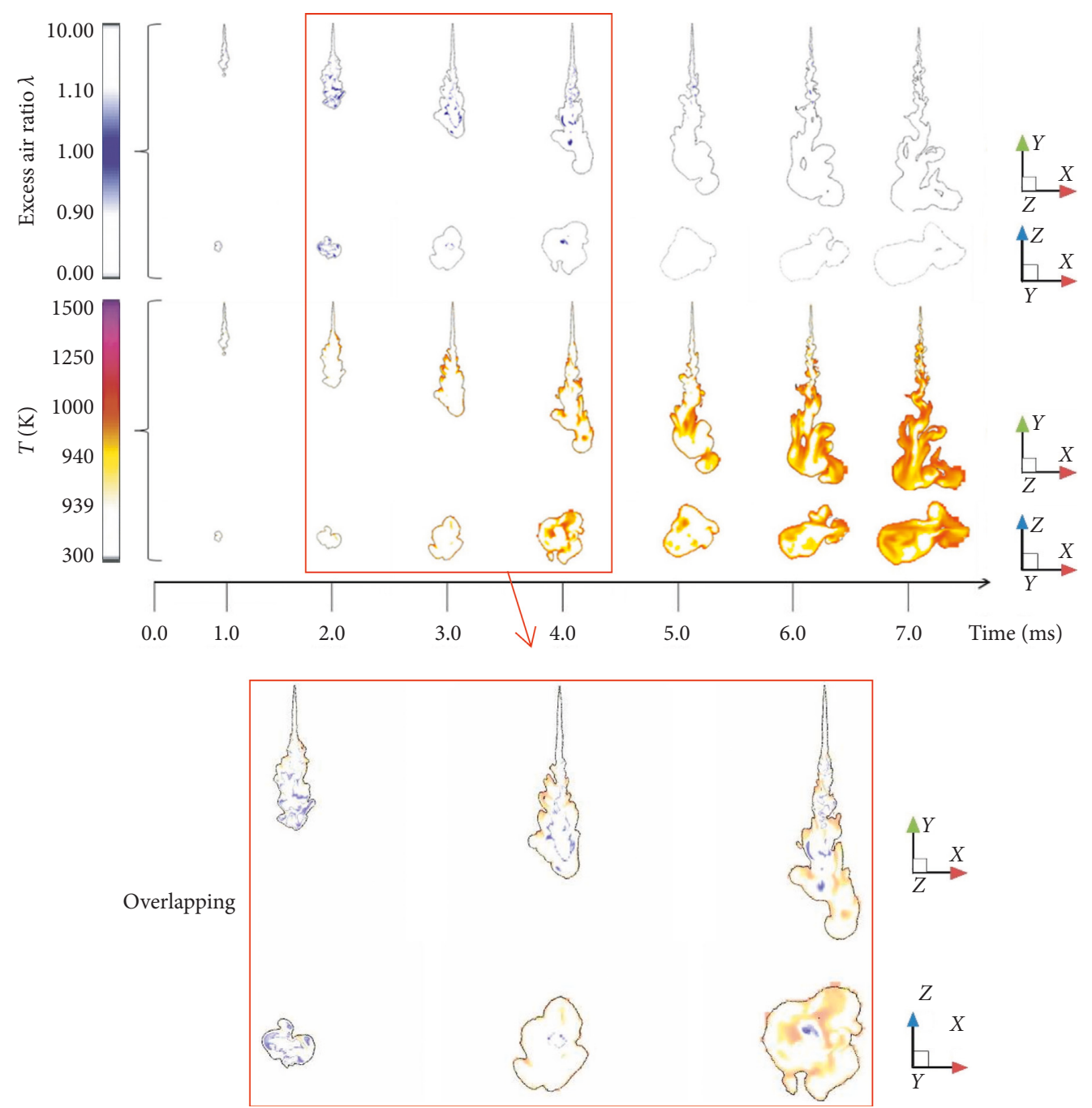

FIgURE 8: Temporal and spatial mismatch of autoignition-suitable concentration and temperature during the mixture formation process of an ethanol spray (surrounding gas conditions: $P=6.5 \mathrm{MPa}, T=1000 \mathrm{~K}$, and $\mathrm{O}_{2} 21$ vol.\%).

ignition point $\left(T_{\mathrm{ig}}\right)$ of ethanol. From this fact, the actual minimum ignition point of ethanol seems to exist between $900 \mathrm{~K}$ and $1000 \mathrm{~K}$ under the surrounding gas pressure condition higher than 5.5 MPa. In case of No. 6 simulation (conditions: $P=9.0 \mathrm{MPa}$ and $T=1200 \mathrm{~K}$ ), as presented in Figure 7, faster lean mixture situation due to higher entrained gas density and shorter ignition delay was obtained compared with the case of No. 5 simulation. This can be achieved by the earlier $\lambda=1$ timing under sufficient temperature for chemical reactions.

In order to investigate the inside structure of an ethanol spray and to understand the physical and chemical conditions/mechanisms of the autoignition phenomenon, we analyzed local $\lambda$ and $T$ distributions focusing on the simultaneous attainment of autoignition-suitable mixture concentration and temperature with an assumption of the minimum ignition point of ethanol as $T_{\mathrm{ig}}=940 \mathrm{~K}$.

Figures 8 and 9 show the above introduced analysis in case of No. 3 (conditions: $P=6.5 \mathrm{MPa}$ and $T=1000 \mathrm{~K}$ ) and No. 5 (conditions: $P=5.5 \mathrm{MPa}$ and $T=1100 \mathrm{~K}$ ) simulations, respectively. For each figure, the upper part indicates the local $\lambda$ distribution of $x-z$ and $x-y$ cross sections. The area of $\lambda=1$ recognized as the autoignition condition in a sort of mixture concentration is coloured blue. The lower part corresponds to $T$ distribution, and the local area of temperature higher than $T_{\mathrm{ig}}=940 \mathrm{~K}$ is coloured orange. The lowest part is the enlarged overlapped images of $\lambda$ and $T$ distributions at the same timing from fuel injection. It is confirmed from Figure 8 (in which the case of autoignition is not observed) that no overlapped region of two colours is found. On the contrary, for the case in Figure 9 (in which the case of autoignition is observed), the overlapped region of two colours is recognized after $4.3 \mathrm{~ms}$ (see the blue circle region in the overlapped image). This timing coincides with the time of drastic temperature rise previously introduced in Figure 6(a). In addition to the timing, the overlapped region coincides with the region of temperature higher than $2200 \mathrm{~K}$ illustrated in Figure 6(b) after fuel injection is finished. Therefore, it seems that autoignition occurs inside the spray at the above-mentioned two-colour-overlapped place and timing. Based on this numerical analysis, the condition of stable autoignition of an ethanol spray seems to be the 


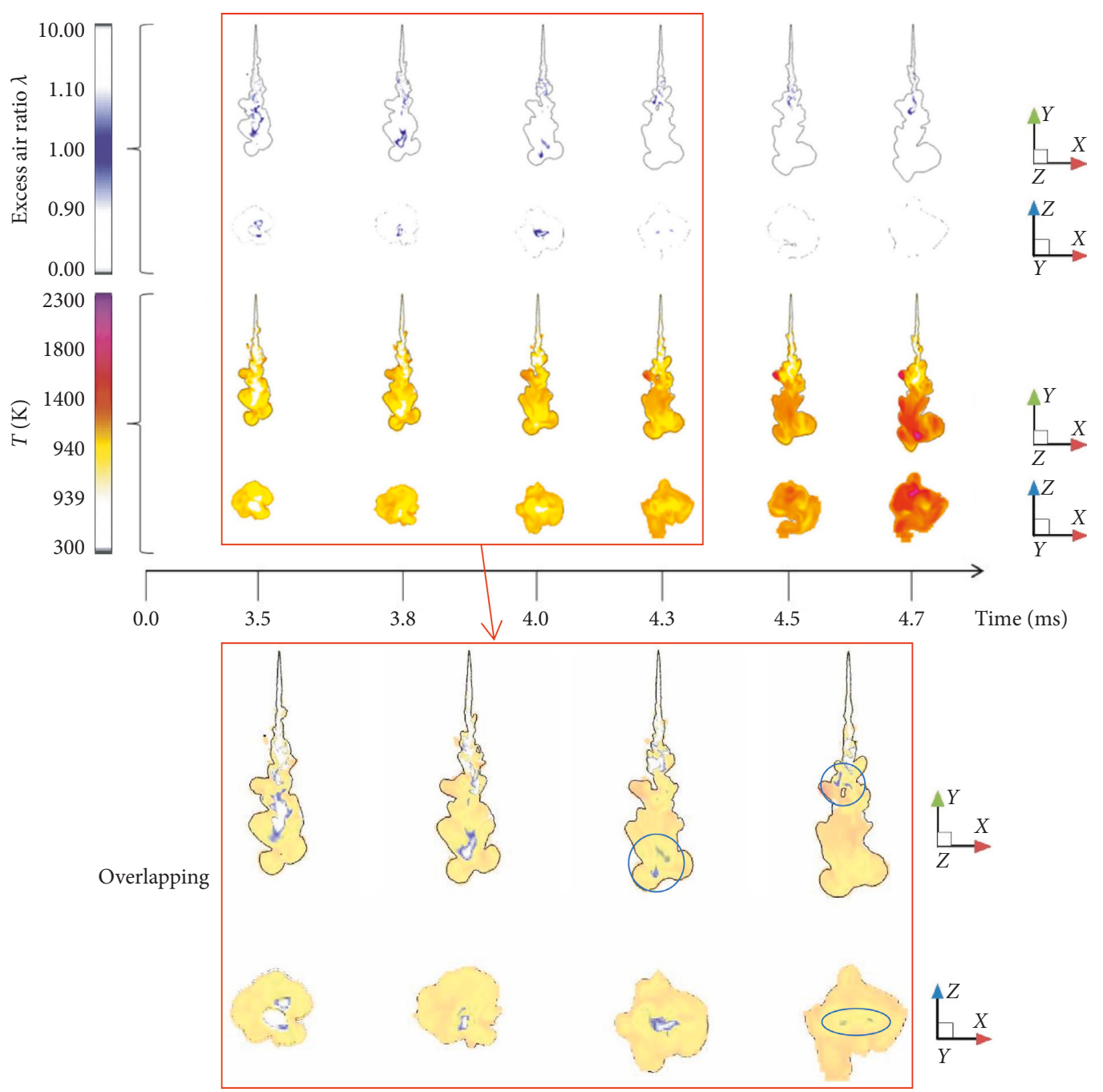

FIGURE 9: Simultaneous attainment of autoignition-suitable concentration and temperature during the mixture formation process of an ethanol spray (surrounding gas conditions: $P=5.5 \mathrm{MPa}, T=1100 \mathrm{~K}$, and $\mathrm{O}_{2} 21$ vol.\%).

existence of the region where $\lambda=1$ and $T>T_{\text {ig }}=940 \mathrm{~K}$ are simultaneously satisfied. In order to realize such concentration and temperature conditions inside a spray by fuel injection, surrounding gas temperature is required higher than $1100 \mathrm{~K}$.

Siebers and Edwards [16] also recommended surrounding gas temperature greater than $1100 \mathrm{~K}$ for stable autoignition of alcohol sprays. Liu et al. [17] examined and reported the autoignition characteristics of an $n$-butanol spray with changing surrounding gas $\mathrm{O}_{2}$ concentration. Their experimental condition of surrounding gas temperature was $1000 \mathrm{~K}$. However, the compression ratio higher than 40 is required for $1100 \mathrm{~K}$ compression temperature with the assumptions of the initial gas temperature of $300 \mathrm{~K}$ and polytropic exponent of 1.35. Compression gas pressure reach to $14.5 \mathrm{MPa}$ with the assumption of $0.1 \mathrm{MPa}$ initial intake gas pressure. Such an extremely high value of compression ratio is not required for conventional diesel technologies because the much increase of friction loss induced by high pressure and sacrification of efficiency is expected. Therefore, it seems to be difficult by simple compression to simultaneously realize compression temperature higher than $1100 \mathrm{~K}$ and compression pressure around 6.5-7.5 MPa that correspond to the feasible compression ratios around 22-24. In our numerical analysis, autoignition was obtained under the surrounding gas condition of $5.5 \mathrm{MPa}$ corresponding to the compression ratio of 19.5 that is lower than that of latest diesel engines; therefore, a higher initial gas temperature before compression by preheating seems to be an effective way to achieve the above introduced requirement of compression gas pressure and temperature. This is an idea from the physical aspect for the establishment of controlled-ignition technology. Another approaching way is from the chemical aspect such as adding a small amount of the ignition improver. Munsin et al. [18, 19] reported the effect of ignition improvers on ignition delay time of ethanol combustion with rapid compression and expansion machine. However, the mechanism of autoignition quality improvement by additives is not chemically revealed yet. For the real engine application, Kaiadi et al. [20] proposed PPC (partially premixed combustion) by the double injection strategy, and they reported the ignition, combustion, and emission 
TABle 5: Matrix of analysis conditions (combination of surrounding gas $P$ and $T$ for an ethanol spray).

\begin{tabular}{|c|c|c|c|c|c|c|}
\hline \multirow{2}{*}{$T(\mathrm{~K})$} & \multicolumn{6}{|c|}{$P$} \\
\hline & $2.5 \mathrm{MPa}$ & $3.5 \mathrm{MPa}$ & $4.5 \mathrm{MPa}$ & $5.5 \mathrm{MPa}$ & $6.5 \mathrm{MPa}$ & $9.0 \mathrm{MPa}$ \\
\hline 800 & No. $2^{\times}$ & & & & & \\
\hline \multicolumn{7}{|l|}{900} \\
\hline 1000 & & & & & No. $3^{\times}$ & No. $4^{\times}$ \\
\hline 1100 & & & & No. $5^{\bigcirc}$ & & \\
\hline 1200 & & & & & & No. $6^{\bigcirc}$ \\
\hline
\end{tabular}

characteristics by using a diesel engine with a high EGR ratio (40\%-70\%) and preheating of intake gas. Their results of ignition and combustion characteristics are reasonable for our recognition of the required conditions for stable autoignition of an ethanol spray. Although PPC may be one of the solutions for ethanol CI engines, the engine operating range is still limited, and the physical and chemical mechanisms from mixture formation up to autoignition must be cleared for further improvement of their technology. The authors, therefore, think that further fundamental studies are needed in order to develop the controlled-ignition technology for the establishment of high-performance CI alcohol engines.

\section{Conclusions}

(1) The condition of stable autoignition of an ethanol spray is the existence of the region where excess air ratio $(\lambda)=1$ and temperature higher than the minimum ignition point of ethanol are simultaneously satisfied during the mixture formation process.

(2) The actual minimum ignition point of an ethanol spray under the high pressure condition such as compression pressure of conventional diesel engines is expected around $940 \mathrm{~K}$, and $1100 \mathrm{~K}$ is recommended as compression gas temperature (entrained gas temperature) to achieve $940 \mathrm{~K}$ inside a spray by fuel injection.

\section{Future Work}

Table 5 indicates the matrix of analysis conditions as the combination of surrounding gas pressure $(P)$ and temperature (T). We decided the range of $P$ and $T$ based on the results obtained in our previous experiments in order to make clear the $P$ and $T$ combination as the surrounding gas condition when stable autoignition occurs for an ethanol spray. At present, just five simulations were completed; therefore, the first task as the future work is to complete this matrix that indicates the required surrounding gas pressure and temperature for stable autoignition of an ethanol spray, and chemical reactions will be analyzed in order to make clear what reaction path is essential/important to induce the chain reaction of combustion. Effect of oxygen concentration of surrounding gas on autoignition of an ethanol spray will be numerically investigated as the next step. In addition to this numerical analysis, experiments (spray visualization tests) will also be conducted for ethanol-diethyl ether blend fuel and neat ethanol by using the original-designed and manufactured RCEM (rapid compression and expansion machine) that can be operated under the same high pressure and temperature conditions of conventional diesel engines. When the autoignition phenomenon of an ethanol spray is revealed from both physical and chemical aspects, reasonable and feasible ideas of controlled-ignition technologies such as the appropriate intake gas flow, shape of the combustion chamber, fuel injection (nozzle size, pressure/duration/timing, and multistage injection), and appropriate EGR rate can be proposed, and their effectiveness is examined by further numerical analysis and experiments.

\section{Nomenclature}

c: $\quad$ Specific heat $(\mathrm{kJ} /(\mathrm{kg} \cdot \mathrm{K}))$

$G$ : Mass $(\mathrm{kg})$

$L_{t h}:$ Stoichiometric air-fuel ratio (-)

$n$ : Polytropic exponent (-)

$P$ : Pressure $(\mathrm{MPa})$

Q: Required/supplied heat $(\mathrm{kJ})$

$S$ : Index of the numerical shadowgraph defined as the root sum square of second-order spatial density gradient in three directions

$T: \quad$ Temperature $(\mathrm{K})$

$t$ : Time (ms)

$\varepsilon: \quad$ Compression ratio $(-)$

$\lambda$ : $\quad$ Excess air ratio $(-)=$ actual air-fuel ratio/

stoichiometric air-fuel ratio

$\gamma: \quad$ Latent heat of evaporation $(\mathrm{kJ} / \mathrm{kg})$.

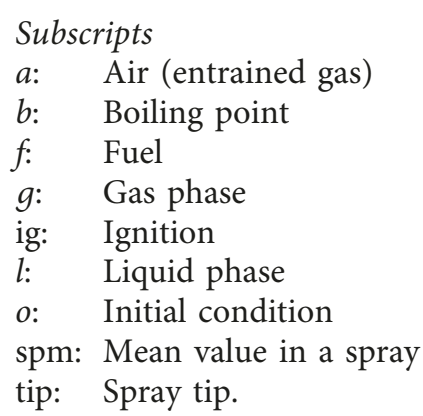

Abbreviations

CFD: Computational fluid dynamics

CI: Compression ignition

EGR: Exhaust gas recirculation

PPC: Partially premixed combustion

TDC: Top dead center.

\section{Data Availability}

The data used to support the findings of this study are available from the corresponding author upon request. 


\section{Disclosure}

The content of this paper was orally presented at the 9th Thai Society of Mechanical Engineers International Conference on Mechanical Engineering held in Phuket, Thailand, December 11-14, 2018.

\section{Conflicts of Interest}

The authors declare that there are no conflicts of interest regarding the publication of this paper.

\section{Acknowledgments}

The authors would like to express special appreciation to the Japanese Ministry of Education, Culture, Sports, Science and Technology and Japan Society for the Promotion of Science for their money support as grant-in-aid for scientific research (16K06135), and the authors also appreciate Mr. A. Umeno for his assistance in creating graphs and visualizing numerical calculation data.

\section{References}

[1] C. Havenith, H. Kuepper, and U. Hilger, "Performance and emission characteristics of the deutz glow plug assisted heavyduty methanol engine," SAE, Evanston, IL, USA, SAE-872245, 1986.

[2] P. Zelenka and P. Kapus, "Development and vehicle application of a multi-fuel DI-alcohol engine," Institution of $\mathrm{Me}$ chanical Engineers-925010, vol. C389/127, pp. 81-87, 1992.

[3] S. J. Dhinagar, B. Nagalingam, and K. V. Gopalakrishnan, "Experimental investigations on the combustion of ethanol in a low heat rejection engine using different methods," SAE, Evanston, IL, USA, SAE-930931, 1986.

[4] W. A. Goetz, C. G. Barringer, and M. A. Bozzelli, "Utilizing neat methanol and glow plug ignition in di diesels: laboratory testing of a single and multi-cylinder engine," SAE, Evanston, IL, USA, SAE-941044, 1986.

[5] T. Seko, Y. Yoshida, I. Yamaguchi, T. Sakai, M. Hori, and Y. K. Kim, "Combustion exhaust emissions of the sparkassisted methanol diesel engine," SAE, Evanston, IL, USA, SAE-861165, 1986.

[6] S. Niemi and J. Pitkanen, "Development of a turbocharged and inter-cooled spark-assisted direct-injection ethanol engine," in Proceedings of 20th International Council on Combustion Engines (CIMAC), London, UK, 1993.

[7] B. Bartunek, U. Hilger, E. Scheid, and G. W. Rogers, "Influence of the methanol fuel composition on performance and exhaust emissions of diesel-derived alcohol engines," SAE, Evanston, IL, USA, SAE-881197, 1988.

[8] A. Ramesh, B. Nagalingam, and K. V. Gopalakrishnan, "Investigation on the design and performance of two types of hot surface ignition engines," SAE, Evanston, IL, USA, SAE921632, 1992.

[9] T. G. Holland, M. N. Swain, and M. R. Swain, "Using ethanol/ diesel mixtures in a compression ignition engine with ignition improver additives," SAE, Evanston, IL, USA, SAE-922191, 1992.

[10] H. Simonsen and J. Chomiak, "Testing and evaluation of ignition improvers for ethanol in a DI diesel engine," SAE, Evanston, IL, USA, SAE Technical Paper 952512, 1995.
[11] H. Saitoh and K. Uchida, "On the main factors governing auto-ignition phenomenon of alcohol spray-a study from the view point of fuel properties -," SAE International Journal of Fuels and Lubricants, vol. 2, no. 1, pp. 911-920, 2009.

[12] Y. Wakuri, "Study on the phenomena of fuel spray in a diesel engine," The Japan Society of Mechanical Engineers: Bulletin of the JSME, vol. 13, no. 9, 1960.

[13] H. Saitoh and K. Uchida, "Surrounding gas pressure and temperature dependence of the spray auto-ignition phenomenon for ethanol-diethyl ether blended fuels," Journal of Research and Applications in Mechanical Engineering, vol. 4, no. 1, pp. 79-86, 2015, (presented at the 6th TSME International Conference on Mechanical Engineering, 2015) Transaction of the TSME 2016.

[14] K. Uchida and H. Saitoh, "Surrounding gas pressure and oxygen concentration dependence of the spray auto-ignition phenomenon for ethanol-diethyl ether blended fuels," Journal of Research and Applications in Mechanical Engineering, vol. 6, no. 1, pp. 1-12, 2016, Transaction of the TSME 2018.

[15] N. M. Marinov, "A detailed chemical kinetic model for high temperature ethanol oxidation," International Journal of Chemical Kinetics, vol. 31, no. 3, pp. 183-220, 1999.

[16] D. L. Siebers and C. F. Edwards, "Auto-ignition of methanol and ethanol sprays under diesel engine conditions," SAE, Evanston, IL, USA, SAE Technical Paper SAE-870588, 1987.

[17] H. Liu, C.-F. Lee, Y. Liu, M. Huo, and M. Yao, "Spray and combustion characteristics of n-butanol in a constant volume combustion chamber at different oxygen concentrations," SAE, Evanston, IL, USA, SAE Technical Paper 2011-01-1190, 2011.

[18] R. Munsin, Y. Laoonual, S. Jugjai, M. Matsuki, and H. Kosaka, "Investigation of effects of ignition improvers on ignition delay time of ethanol combustion with rapid compression and expansion machine," SAE, Evanston, IL, USA, SAE Technical Paper 2012-01-0854, 2012.

[19] R. Munsin, Y. Laoonual, S. Jugjai, M. Matsuki, and H. Kosaka, "Effect of glycerol ethoxylate as an ignition improver on injection and combustion characteristics of hydrous ethanol under CI engine condition," Energy Conversion and Management, vol. 98, pp. 282-289, 2015.

[20] M. Kaiadi, B. Johansson, M. Lundgren, and J. A. Gaynor, "Sensitivity analysis study on ethanol partially premixed combustion," SAE, Evanston, IL, USA, SAE Technical Paper 2013-01-0269, 2013. 


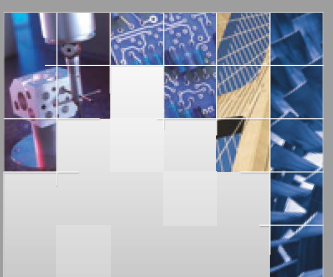

\section{Enfincering}
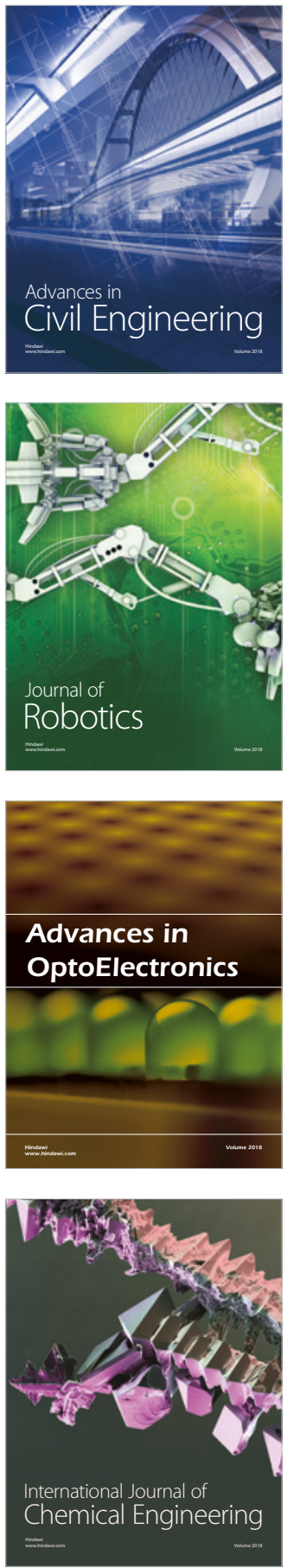

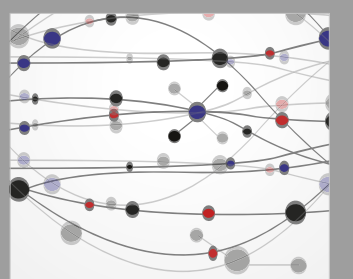

\section{Rotating \\ Machinery}

The Scientific World Journal

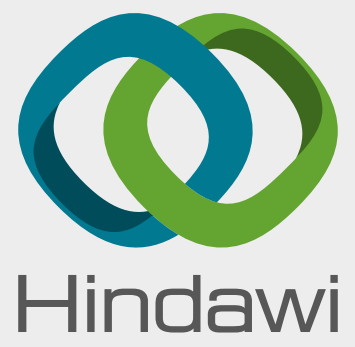

Submit your manuscripts at

www.hindawi.com
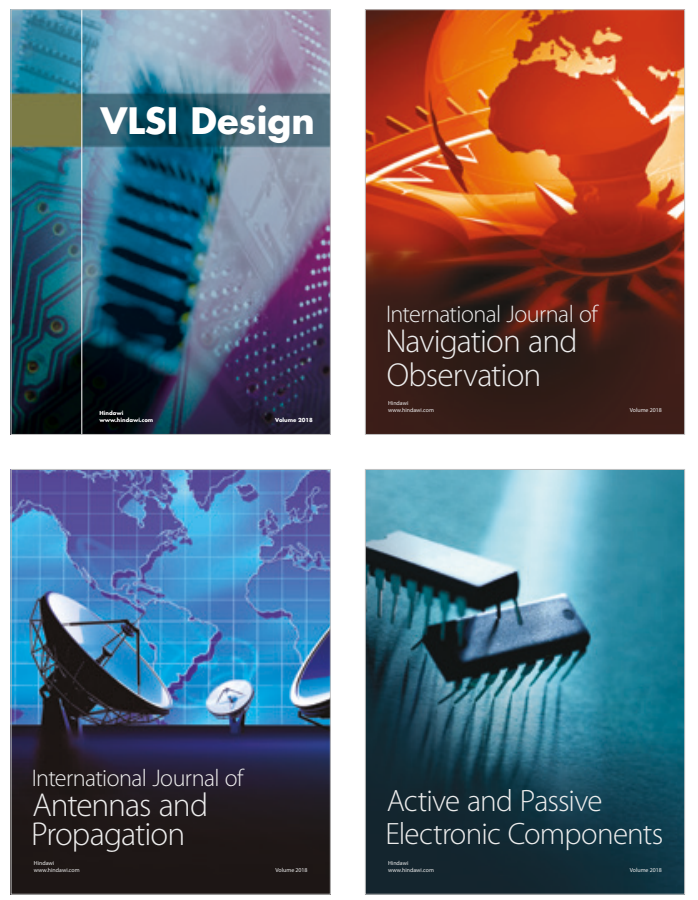
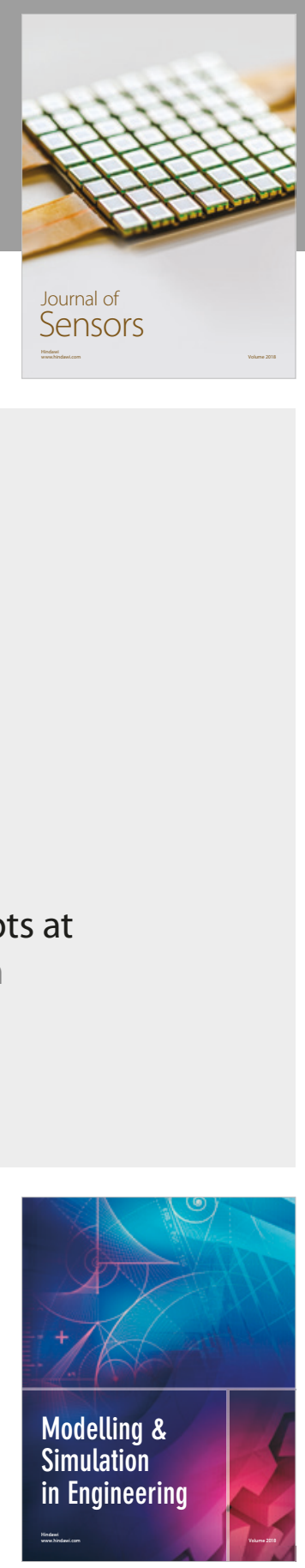

\section{Advances \\ Multimedia}
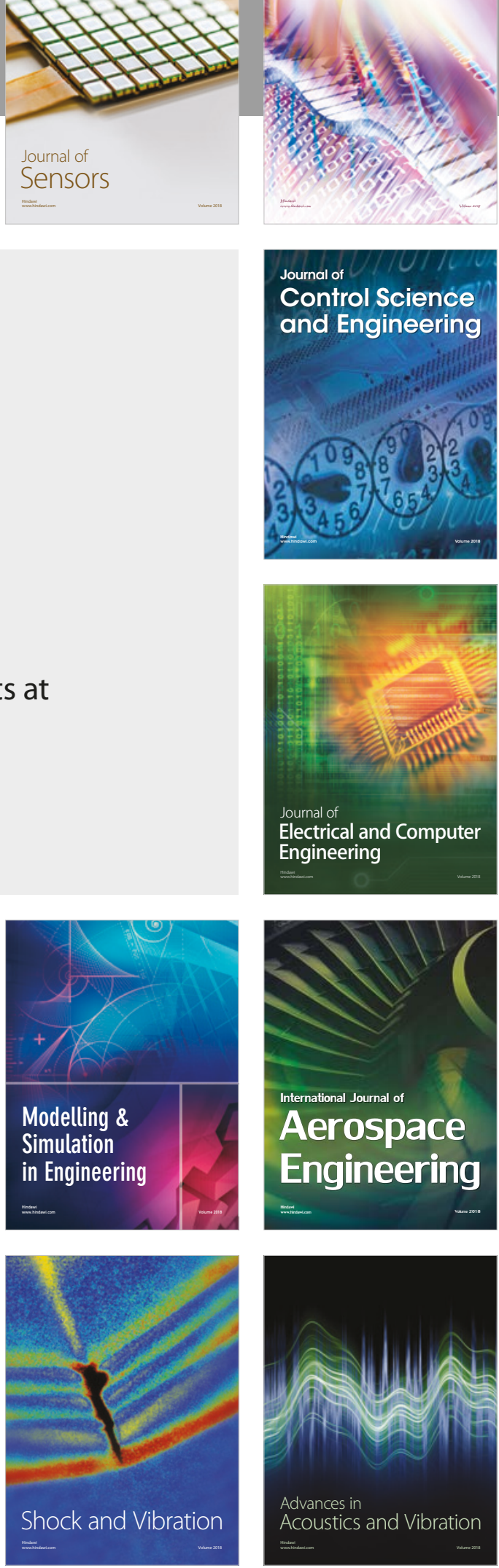